\title{
Fundeb, remuneração docente e dívida pública: uma discussão sobre disputa pelo fundo público (2008 - 2016)
}

\author{
Fundeb, teaching remuneration and public debt: \\ a discussion on the dispute over the public fund (2008 - 2016) \\ Fundeb, la remuneración docente y la deuda pública: \\ una discusión sobre la disputa sobre el fondo público (2008 - 2016)
}

MARCUS QUINTANILHA DA SILVA

Orcid ld: http://orcid.org/0000-0002-8305-0024

Faculdade São Braz

Resumo: Esse artigo teve como objetivo compreender os efeitos da complementação da União no Fundeb para a remuneração de professores públicos municipais entre 2008 e 2016. Situa-se o problema no contexto de disputa pelo fundo público, ampliando o debate com a alocação de recursos federais para a rolagem da dívida pública. A metodologia se baseou em um estudo panorâmico de compreensão de dados quantitativos, evidenciando a influência dos recursos da União na valorização da remuneração docente no Brasil, bem como algumas tendências da disputa pelo fundo público após o período analisado.

Palavras-chave: Política educacional, Fundo público, remuneração docente, Fundeb, Dívida pública.

Abstract: This article aimed to understand the effects of the Federal Government complementation at Fundeb for the remuneration of municipal public teachers between 2008 and 2016. The problem is situated in the context of a dispute over the public fund, expanding the dialogue with the allocation of federal resources for the rollover of public debt. The methodology was based on a panoramic study to understand quantitative data, showing the influence of the Federal Government resources in the valorization of teaching remuneration in Brazil, as well as some tendencies of the dispute for the public fund after the analyzed period.

Keywords: Educational politics, Public fund, teaching remuneration, Fundeb, Public debt.

Resumen: Este artículo tuvo como objetivo comprender los efectos de la complementación de la Unión en Fundeb para la remuneración de los maestros públicos municipales entre 2008 y 2016. El problema se sitúa en el contexto de una disputa sobre el fondo público, ampliando el debate con la asignación de recursos federales para la renovación de la deuda pública. La metodología se basó en un estudio panorámico de comprensión de datos cuantitativos, que muestra la influencia de los recursos de la Unión en la valoración de la remuneración docente en Brasil, así como algunas tendencias de la disputa por el fondo público después del periodo analizado.

Palabras-clave: Politica educativa, Fondo público, remuneración docente, Fundeb, Deuda pública. 


\section{INTRODUÇÃO}

$\mathrm{Na}$ contemporaneidade do Estado moderno, o fundo público exerce um papel estrutural na dinâmica estatal, seja no contexto de acumulação e/ ou da distribuição da riqueza socialmente produzida. Nesse sentido, assumese que, em um estudo sobre remuneração de professores, tema de estudos em políticas educacionais (SOUZA, 2016), o movimento de alocação de recursos para a valorização do profissional do magistério se insere em um cenário de busca de melhoria da qualidade de vida do docente e atratividade na profissão (GROCHOSKA, 2015; SILVA, 2019).

Como consequência, entende-se que a ampliação das condições de valorização de tais profissionais compõe uma premissa importante para que a população tenha acesso a uma educação pública de qualidade, condição que se dá essencialmente a partir da alocação do fundo público para tal. Nesse viés, este trabalho emerge com o objetivo de compreender os prováveis efeitos da complementação da União no Fundeb para a remuneração de professores públicos municipais entre 2008 e 2016.

Assume-se como método investigativo o materialismo histórico dialético. Por essa leitura e compreensão de cunho marxista na análise das políticas sociais, Behring e Boschetti (2011) compreendem sua utilidade na medida em que busca uma perspectiva relacional entre sujeito e objeto, considerando as múltiplas causalidades de um determinado fenômeno. Adotando a perspectiva de Poulantzas (2015), de que o Estado moderno é uma arena de disputa, mas com uma ossatura que lhe é própria e pautada no constante conflito de interesses, entende-se que "as políticas sociais não podem ser analisadas a partir de sua expressão imediata como fato social isolado" (BEHRING; BOSCHETTI, 2011, p. 39), e sim como expressões das contradições da realidade material em um determinado momento histórico, ou seja, não se constituem como um produto fixo e imutável.

Nesse sentido, entende-se que o estudo da ação do Estado, particularmente nas políticas públicas, precisa considerar os pontos de vista: a) histórico, relacionando o surgimento da política à materialidade das questões sociais; b) econômico, estabelecendo relações de questões econômicas e seus efeitos para as condições de vida da classe trabalhadora, bem como o caráter específico de cada momento histórico, e; c) político, buscando reconhecer e identificar diversos posicionamentos das forças políticas em busca da satisfação de seus interesses, inclusive no que tange ao papel do Estado.

Para o fomento da discussão, foi realizada uma revisão crítica da literatura em torno da disputa pelo fundo público, um trabalho preliminar caracterizado como uma síntese de estudos sobre um tema e, consequentemente, 
evidenciando a existência de um assunto. Posteriormente, os dados quantitativos foram abordados no sentido de compreendê-los, considerando que a estatística é importante para compreensão do fenômeno, mas, para um estudo com variáveis explicativas complexas que envolvem o campo sociológico, é necessário um estudo teórico prévio (SELZ, 2015) e, neste caso, de ações materializadas nas políticas públicas para leitura dos dados. O ponto de partida empírico utilizou como fontes de informação alguns dados trabalhados em Silva (2019) com base na Relação Anual de Informações Sociais - Rais, o Sistema de Informações sobre Orçamentos Públicos em Educação - Siope e os estudos da Auditoria Cidadão da Dívida sobre o orçamento do governo federal executado ${ }^{1}$.

O aporte teórico insere a discussão do financiamento da educação no Brasil, o papel da complementação financeira da União ao Fundo de Manutenção e Desenvolvimento da Educação Básica e Valorização dos Profissionais da Educação - Fundeb, a lei n. 11.738/2.008 e o crescimento da financeirização da riqueza pela via do dispêndio financeiro do fundo público federal para os serviços de rolagem da dívida pública em um contexto de disputa pelo fundo público.

Evidencia-se que o cenário favorável à valorização docente entre 2008 e 2016 pode estar ameaçado em caso de finalização do Fundeb ou redução da complementação financeira da União, fruto de um novo contexto de ordenação de prioridades do fundo público, em que a educação parece estar sofrendo os primeiros efeitos da Emenda Constitucional n. 95/2016, bem como o domínio histórico dos últimos anos do dispêndio financeiro para rolagem da dívida pública na execução orçamentária do fundo público federal.

\section{O FUNDO PÚBLICO EM DISPUTA: APORTES TEÓRICOS}

Esta seção visa a compor um debate sobre a importância do fundo público como elemento estrutural ao desenvolvimento do capitalismo e um objeto em disputa, discutindo possibilidades de retorno do fundo público à população e situando o debate no caso brasileiro, particularizando o papel da União no financiamento da educação e na remuneração docente entre 2008 e 2016.

Em uma definição minimalista de fundo público, pode-se afirmar que se trata da soma de recursos arrecadados pelo Estado, onde os tributos, pagos de forma direta ou indireta, envolvem taxações da sociedade, seja no âmbito da cobrança dos assalariados que vendem sua força de trabalho e/ou dos detentores do grande capital. A caracterização do referido fundo perpassa por reflexões da

1

Associação sem fins lucrativos que, desde 2001, atua de forma aberta com cidadãos e entidades da sociedade civil preocupados com endividamento público, por reconhecer neste um agravante dos problemas nacionais. 
dinâmica contemporânea e os efeitos que o retorno da arrecadação pública pode proporcionar à população. Nesse viés, os estudos de Oliveira (1998), Salvador (2010a, 2010b), Pochmann (2004) e Behring e Boschetti (2011), auxiliam nesse entendimento.

A ideia de fundo público, particularmente no envolvimento deste na influência por melhores condições de vida da população, tem diversos pontos de partida na literatura. Pochmann (2004) delimita o fim da Segunda Guerra Mundial como um momento histórico em que a redistribuição da riqueza passou a ocorrer com maior efetividade, através da tributação dos mais ricos e a transferência de recursos, via políticas sociais, para a população com maior vulnerabilidade social. Esse processo não só buscou essa redistribuição, como teve em sua agenda a retirada do mercado do monopólio da evolução da economia e da administração da força de trabalho, tornando a progressividade tributária sobre a renda e o patrimônio uma inovação, bem como propiciou o retorno do fundo público através da ampliação de serviços públicos.

Compreendendo a importância do fundo público, Salvador (2010b, p. 607) afirma que este, na atualidade, "envolve toda a capacidade de mobilização de recursos que o Estado tem para intervir na economia, além do próprio orçamento, as empresas estatais, a política monetária comandada pelo Banco Central para socorrer as instituições financeiras etc.”. Ou seja, por meio das suas políticas fiscais, se constroem possibilidades de intervenção na economia. Seu papel estrutural permite afirmar que a arrecadação pública, independentemente da concepção de Estado adotada por determinado Governo, sempre terá algum tipo de retorno à população.

Para Oliveira (1998), o fundo público deixou de ser somente uma soma de recursos, mas um ex-ante das condições proporcionadas para maior taxa de lucro do capitalista, em que seu papel estruturante transita entre a base do desenvolvimento do capital e/ou melhoria das condições de vida da população, por ser o responsável na mudança das condições de redistribuição da riqueza socialmente produzida.

No caso das possibilidades de atuação do fundo público para a ampliação de acumulação de capital, Salvador (2010a, p. 91) entende que o fundo público "participa indiretamente da reprodução geral do capital, seja por meio de subsídios, negociação de títulos e garantias de financiamentos dos investimentos dos capitalistas, seja como elemento presente e importante na reprodução da força de trabalho", outra via de alocação da riqueza socialmente produzida arrecadada por tributos. 
Em um sistema capitalista, os que não possuem os instrumentos de produção ou produtos do mercado financeiro necessitam vender sua força de trabalho, recebendo por isso o que se denomina de salário direto, quantia resultante dessa venda que é paga em espécie ao trabalhador. O fundo público como um pressuposto pode ser um meio de melhoria da vida de grande parte da população, particularmente pela via do salário indireto, conceituado por Oliveira (1998) como a gama se serviços/direitos ofertados pelo Estado que, com seu crescimento, podem liberar parte do salário direto ou da renda domiciliar para o consumo de bens e serviços.

O fundo público, portanto, como elemento estrutural no desenvolvimento do capitalismo contemporâneo, é fundamental no desenvolvimento das políticas sociais, se situando como "um lugar relevante na alocação do fundo público, a pender, claro, da correlação de forças políticas e de elementos culturais em cada formação nacional" (BEHRING, 2004, p. 164). Seu perfil de alocação, baseado na ordenação de prioridades do poder público, característica marcante do Estado Moderno (POGGI, 1981), "reflete as disputas existentes na sociedade de classes, em que a mobilização dos trabalhadores busca garantir o uso da verba pública para o financiamento de suas necessidades, expressas nas políticas públicas" (BEHRING; BOSCHETTI, 2011, p. 174).

Mesmo com a evolução do Estado Social, particularmente nos países desenvolvidos, a ofensiva do capital trouxe sérios riscos à proteção social e conquistas de direitos após a Segunda Guerra Mundial, em um modelo de acumulação capitalista capitaneado pela esfera financeira (SALVADOR, 2010a). A disputa pelo fundo público se acirra na medida em que, em meados da década de 1970, o keynesianismo é apontado como um dos fatores da crise do capitalismo, quando, na verdade, a mesma não tem sua gênese na falta de mercado ou excesso de despesas com políticas sociais, mas sim na valorização de capitais e aperto dos lucros. Com a busca pela expansão global de mercados, aumentou-se a concorrência, gerando como consequência a redução de preços, induzindo o capitalista a intensificar a exploração do trabalhador. Nesse viés, o "baixo retorno dos investimentos produtivos, ou seja, a queda na rentabilidade, leva a uma fuga do capital do setor produtivo para a esfera financeira, agindo de forma especulativa" (SALVADOR, 2010a, p. 930), ou seja, se pautando na antecipação de formação de preços futuros de produtos do capital, ativos como terrenos urbanos, propriedades imobiliárias, ações e títulos públicos.

Essas transformações, impulsionadas na década de 1980 pelo sistema financeiro internacional, mobilizou os bancos a adotar estratégias que pudessem garantir novas formas de acumulação de capital, particularmente a partir de títulos negociáveis e contratos associados aos mesmos. Com isso, houve um 
enriquecimento privado, sem necessariamente resultar em um investimento produtivo. De acordo com Salvador, a nova etapa de acumulação financeira, centralizada na dívida, caracterizou os dividendos "como um mecanismo importante de riqueza e acumulação. A pressão dos mercados sobre os grupos industriais impõe novas normas de rentabilidade e exigências de redução de custos salariais, aumento de produtividade e flexibilidade nas relações de trabalho" (SALVADOR, 2010a, p. 98).

No caso dos países da América Latina, particularizando o caso brasileiro, o aumento do dispêndio financeiro a serviço da dívida marcou uma onda de crises financeiras, promovendo o Fundo Monetário Internacional como tutor das políticas econômicas em países em desenvolvimento. Nessa análise, destaca-se, no contexto de disputa pelo fundo público, os princípios da intervenção estatal do neoliberalismo para evitar uma crise generalizada das economias de mercado. Segundo Anderson (1995), a intenção foi a de manter um Estado forte, mas no sentido de romper o poder dos sindicatos, intervir minimamente nas políticas sociais e promover a estabilidade monetária com o fim de objetivar superávit primários.

Nesse viés, a crítica neoliberal sobre a proteção social sob a forma de políticas públicas redistributivas é focada na oneração que esta faz aos acumuladores de capital, pois, ao aumentar o consumo das classes populares, enfraquece a poupança interna, culminando no aumento das taxas de juros e a diminuição de investimento privado (SALVADOR, 2010a).

O resultado da disputa pelo fundo público em benefício do socorro de instituições financeiras às custas dos impostos pagos pelos cidadãos é característica presente em todas as crises financeiras das últimas três décadas. A financeirização da riqueza tem implicações diretas sobre as políticas sociais, muito particularmente na destinação financeira onde há, no caso brasileiro, Desvinculação de Receitas da União (DRU), um cerne importante de exploração de capitais em prol do serviço da dívida. Salvador resume essa discussão ao elencar que

Com a financeirização da riqueza, os mercados financeiros disputam mais recursos do fundo público pressionado por destinação cada vez mais elevada de recursos para a esfera financeira, que passa pela remuneração dos títulos públicos emitidos pelas autoridades monetárias e negociados no mercado financeiro, os quais se constituem importante fonte de rendimentos para os investidores institucionais, além da transferência de recursos do orçamento público para o pagamento de juros da dívida pública que é o combustível alimentador dos rendimentos dos rentistas (SALVADOR, 2010a, p. 116). 
Além disso, generosos incentivos fiscais e isenção de tributos para o mercado financeiro às custas do fundo público, sempre pautados em um discurso de crise fiscal, são inerentes a essa disputa. Com isso, concorda-se com Behring e Boschetti (2011, p. 174) quando, ao caracterizar o fundo público, afirmam que o capital, com sua força hegemônica, "consegue assegurar a participação do Estado em sua reprodução por meio de subsídios econômicos [...] com destaque para a rolagem da dívida pública".

Portanto, na discussão supracitada, o fundo público é compreendido como um objeto de valor com várias possibilidades na sua alocação, particularmente na melhoria de vida da população e/ou na ampliação da acumulação de capital. A questão central é que, em determinado momento histórico, o salário indireto passou a compor o padrão de financiamento público, marcado por "regras assentidas pelos principais grupos sociais e políticos. Criou-se uma esfera pública ou um mercado institucionalmente regulado" caracterizando uma "esfera pública que atende à burguesia, mas não é essencialmente burguesa” (OLIVEIRA, 1998, p. 21), atendendo aos anseios do capital, mas com regras nem sempre consensuais.

No contexto em que o fundo público não é somente a arrecadação per si, mas um elemento estrutural em disputa, em que projetos de sociedade e a ordenação de prioridades do poder público podem ser traduzidas em maiores parcelas de recursos públicos, é oportuno discutir o financiamento da educação, buscando elementos que auxiliem a compreender o quanto a educação e, particularmente, a remuneração docente, foram contemplados pela ordenação de prioridades do governo federal, dialogando posteriormente com o seu contraponto - osf dispêndios com o serviço da dívida pública.

\section{REMUNERAÇÃO DE PROFESSORES PÚBLICOS MUNICIPAIS X DISPÊNDIO COM A ROLAGEM DA DÍVIDA PÚBLICA: O FUNDO PÚBLICO FEDERAL EM DISPUTA}

Em grande parte das nações, houve um crescimento percentual do salário indireto pelo Estado, liberando o salário direto para o consumo das massas, particularmente em educação, saúde e programas de garantia de ampliação de renda (BEHRING; BOSCHETTI, 2011). Mesmo no caso brasileiro, em um contexto de tensão entre as políticas sociais e a pressão por parte de segmentos conservadores a favor da acumulação de capital e a retomada de um Estado caritativo e assistencialista.

Mesmo que a Constituição Federal de 1988 elenque uma série de competências de responsabilidade dos entes federados - União, estados, municípios e Distrito Federal - delimitam-se algumas políticas públicas do governo 
federal entre 2008 até 2016 que movimentaram o fundo público, culminando em uma provável influência na remuneração de professores da educação básica dos municípios. O financiamento da educação no Brasil, com especial destaque para a política de fundos, a lei n. 11.738/2008, bem como o contraponto na disputa pelo fundo público, a dívida pública, foram os elementos considerados nesse contexto.

No caso brasileiro, é necessário considerar que, além de os recursos do fundo público serem concentrados na União, fazendo desse o ente federado com maior capacidade de tributação e financiamento, há uma vultuosa concentração na alocação de recursos nos serviços da dívida pública (BEHRING; BOSCHETTI, 2011). Nesse sentido, entende-se que há potencial econômico para que a União aloque seu fundo público para a melhoria da qualidade da educação e, mais especificamente, na remuneração de profissionais do magistério público municipais, tida como uma importante condição de valorização profissional e de vida (GROCHOSKA, 2015; SILVA, 2019; CAMARGO; JACOMINI, 2011).

Esse perfil de arrecadação também é pautado na diferença de potencial tributário regional. Historicamente, o desenvolvimento econômico do país foi desigual nas regiões brasileiras, com uma desvantagem considerável nas regiões Norte e Nordeste em relação às demais (ARAÚJO, 2013). Essa condição estrutural, consequentemente, reverbera na desigualdade de potencial de investimento em educação entre os entes federados.

Nesse viés, é importante algumas considerações sobre a estrutura de financiamento da educação no Brasil, particularmente no que tange à vinculação de receitas e às políticas de fundos, mesmo considerando que outras fontes de receitas, como a Contribuição Social do Salário Educação e repasses voluntários oriundos de programas específicos do governo federal, são impactantes nas políticas educacionais, mas que, pelo foco na remuneração de professores, não serão objetos de discussão neste trabalho.

No caso da primeira questão, o art. 212 da Constituição Federal de 1988 vincula um percentual mínimo de $25 \%$ de impostos e transferências constitucionais para Manutenção Desenvolvimento do Ensino (MDE) por parte dos estados, Distrito Federal e municípios (BRASIL, 1988) para aplicação no âmbito da atuação prioritária dos entes federados, definida no art. 211 da referida Carta Magna, modificada pela EC n. 14/1996, sendo a educação infantil e ensino fundamental para os municípios, ensino fundamental e ensino médio para os estados e, no caso da União, financiando as instituições de ensino públicas federais e atuando de forma redistributiva e supletiva na busca da equalização de oportunidades educacionais e padrão mínimo de qualidade do ensino mediante assistência técnica e financeira aos entes da federação. 
Todavia, com o novo regime fiscal consumado pela aprovação da Emenda Constitucional n. 95/2016, foi estabelecido para os próximos 20 anos um teto que limitou as despesas primárias, inclusive do Poder Executivo Federal, que incluem as políticas educacionais, congelando provisoriamente o dispositivo constitucional de vinculação de receitas da União de $18 \%$, pois, desde o início de 2017, o investimento em educação ficou limitado ao valor gasto no ano anterior, reajustado pelo IPCA - Índice Nacional de Preços ao Consumidor Amplo.

Essa vinculação é acompanhada, desde 1996, pela política de fundos, caracterizada por uma tensão que envolve os recursos vinculados e a necessidade de expansão do direito à educação de qualidade e enfrentamento das desigualdades educacionais no Brasil (GOUVEIA; SOUZA, 2015). Atualmente, essa política é denominada Fundeb (Fundo de Manutenção e Desenvolvimento da Educação Básica e Valorização dos Profissionais da Educação), criada pela Emenda Constitucional n. 53/2006 e regulamentada pela lei n. 11.494/2007.

O Fundeb opera por meio de 27 fundos em nome dos estados e Distrito Federal, em que a redistribuição dos recursos tem por critério o número de matrículas da educação básica, de acordo com os dados do último Censo Escolar, e a modalidade a qual a mesma está vinculada, sendo que, para essa redistribuição, são computados os estudantes matriculados no âmbito da atuação prioritária do ente federado. Em consequência, a aplicação dos recursos do fundo deve ser direcionada à responsabilidade educacional da educação básica prevista na Constituição Federal de 1988.

Anualmente é calculado um valor anual mínimo por aluno (VAA) definido nacionalmente, em que as matrículas vinculadas são ponderadas por dezenove fatores que variam de acordo com etapa e modalidade, de 0,8 a 1,3, tendo como base o valor de referência 1 dos anos iniciais do ensino fundamental urbano. A composição é de $20 \%$ de alguns impostos estaduais e repasses constitucionais aos estados e transferências constitucionais municipais, entre eles os impostos sobre circulação de mercadorias e serviços, propriedade de veículos automotores e os fundos de participação dos municípios e estados. A subvinculação dos recursos do Fundeb obriga o gestor público a investir não menos de 60\% desses recursos com pagamento dos profissionais do magistério da educação básica em efetivo exercício, destinando o restante à manutenção e desenvolvimento do ensino.

Aos fundos estaduais que não conseguem arrecadar esse valor, a União atua em caráter complementar em um piso de $10 \%$ da arrecadação nacional do fundo. No percurso histórico entre 2008 e 2016, a complementação da União se constituiu como uma importante ação da política nacional de redistribuição de recursos, possibilitando melhores condições aos municípios de estados que não atingiam o VAA. Com um estado da Região Norte e oito do Nordeste, é possível 
visualizar no gráfico 1 que na comparação 2008 - 2016 houve um aumento do impacto percentual da complementação financeira da União nesses estados, fruto da própria dinâmica do Fundeb, que a partir de 2007 tinha na sua própria formulação a ampliação das matrículas contempladas pelo fundo progressivamente até 2010. A receita estimada do Fundeb em 2008 era de $\mathrm{R} \$ 61.944 .570 .000,20$ e se ampliou para $\mathrm{R} \$ 136.937 .461 .000,40$, aumento aproximado de $121 \%$, percentual bem acima da inflação acumulada no corrente período com base no Índice Nacional de Preços ao Consumidor (INPC), 60,05\%, o que indica um aumento real significativo nas receitas do fundo.

\section{Gráfico 1 - Impacto da complementação da União no Fundeb estadual - 2008 - 2016}

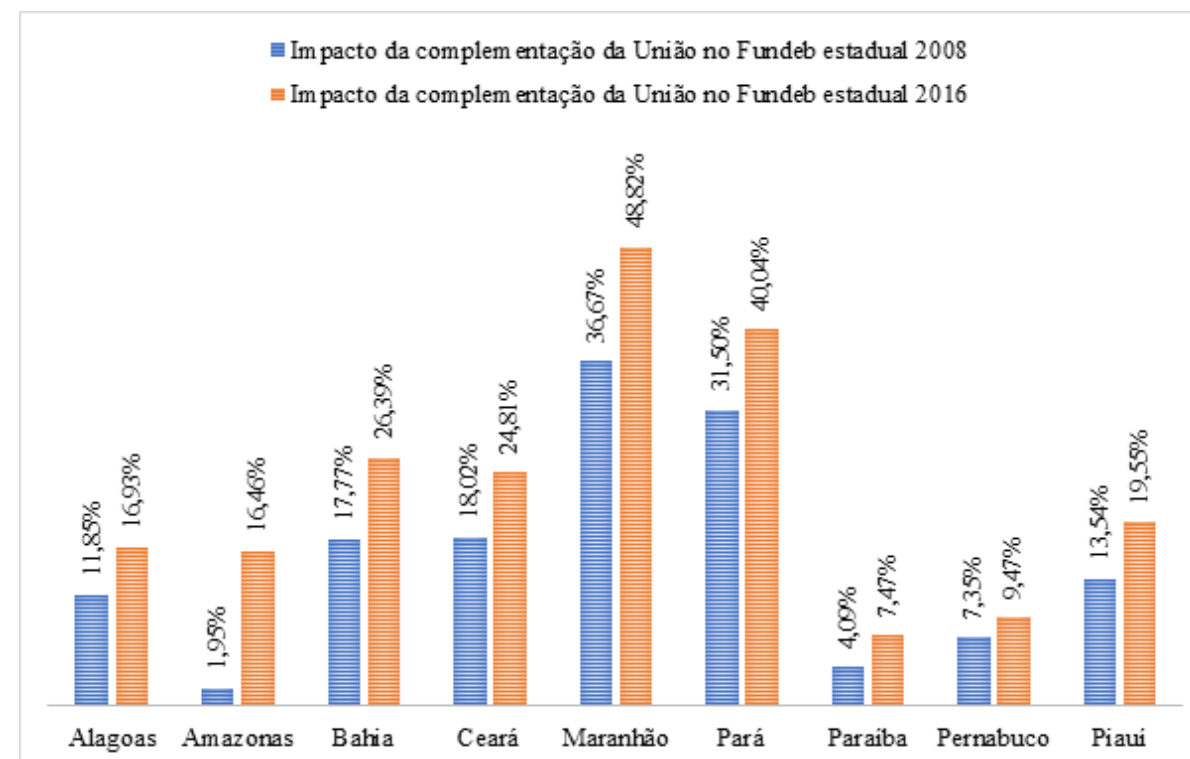

Fonte: Siope $(2008,2016)$. Dados elaborados pelo autor (2020).

Mesmo que os impostos estritamente municipais não entrem no sistema de arrecadação, algumas pesquisas em âmbito nacional e regional apontam para o papel de diminuição da desigualdade e aumento de potencial de investimento para a valorização da remuneração docente (ARAÚJO, 2013; POLENA, 2016), apesar do reconhecimento da insuficiência de promover um cenário igualitário remuneratório.

Ainda que os impostos municipais não constem na lista de repasse para o Fundeb, influenciando na diferenciação de potenciais de investimento (ARAÚJO, 2013), não se descarta o Fundeb como ferramenta de diminuição da desigualdade 
no financiamento educacional. Todavia, o papel de complementação da União é fundamental. Por se tratar de um fundo de redistribuição estadual, sua participação é imprescindível para que o Fundeb atinja seu papel redistributivo em estados com menor arrecadação.

Silva (2019) elaborou uma pesquisa sobre remuneração por hora com professores públicos municipais de 3.286 municípios, com base nos vínculos de trabalho de professores registrados na Relação Anual de Informações Sociais - Rais dos anos de 2008, 2010, 2012, 2014 e 2016, conforme a tabela 1. Foi perceptível o aumento real da média de remuneração docente por hora entre os anos de 2008 e 2016, além da diminuição no coeficiente de variação, ou seja, as remunerações médias tiveram resultados menos variados no comparativo entre as duas pontas da série histórica, 2008 e 2016.

Outra questão é que os menores rendimentos aumentaram significativamente, particularmente até $50 \%$ dos casos que se encaixavam nesse perfil. A média remuneratória dos $25 \%$ dos vínculos com menor remuneração aumentou em $56,77 \%$, enquanto no intervalo dos vínculos de docentes de $25 \%$ e $50 \%$, esse aumento é de $47,43 \%$, e entre $50 \%$ e $75 \%$, a ampliação real é de $34,86 \%$. A tabela 1 auxilia nessa compreensão.

\section{Tabela 1 - Remuneração média por hora em valores reais dos professores públicos municipais no Brasil - 2008 - 2016}

\begin{tabular}{|c|c|c|c|c|c|}
\hline Estatísticas & REM/HORA 2008 & REM/HORA 2010 & REM/HORA 2012 & REM/HORA 2014 & REM/HORA 2016 \\
\hline Casos & 1.298 .573 & 1.420 .045 & 1.612 .526 & 1.734 .804 & 1.707 .845 \\
\hline Média & $\mathrm{R} \$ 17,58$ & $\mathrm{R} \$ 18,68$ & $\mathrm{R} \$ 21,43$ & $\mathrm{R} \$ 23,29$ & $\mathrm{R} \$ 23,63$ \\
\hline Mediana & $\mathrm{R} \$ 13,33$ & $\mathrm{R} \$ 14,55$ & $\mathrm{R} \$ 17,46$ & $\mathrm{R} \$ 19,03$ & $\mathrm{R} \$ 19,65$ \\
\hline $\begin{array}{c}\text { Coeficiente de } \\
\text { Variação }\end{array}$ & $86,33 \%$ & $84,16 \%$ & $76,66 \%$ & $75,48 \%$ & $72,85 \%$ \\
\hline
\end{tabular}

Fonte: Adaptado de Silva (2019).

Na perspectiva de Masson (2017), os planos de carreira e remuneração no Brasil são efetivados de forma muito variada. Nesse viés, as desigualdades remuneratórias no sistema/rede de ensino podem ser mantidas, ampliadas ou reduzidas. Na perspectiva da regionalidade, é possível colher outras perspectivas desse panorama nacional e, neste caso, a complementação da União para o Fundeb pode auxiliar na compreensão do fenômeno.

Agrupando os municípios por região, o período analisado se caracteriza pela região Nordeste com um ponto de partida inferior em termos de média remuneratória em 2008. A região Sudeste, por exemplo, apresentava neste ano 
uma média de remuneração de professores públicos municipais 51\% maior que a região supracitada. Essa diferença percentual cai para 5,2\%, fato relacionado a uma maior ampliação real da média remuneratória nordestina no período.

Nesse panorama, a complementação da União parece ser um elemento fortemente explicativo para esse cenário, pois, dos 9 estados que historicamente não atingem o valor mínimo anual por aluno previsto anualmente para redistribuição do Fundeb, 8 são do Nordeste. Pela comparação entre os anos de 2008 e 2016, é possível afirmar que o papel do governo federal nesse período, mantendo o complemento ao fundo na redistribuição de recursos dentro de cada estado, foi importante na redução da desigualdade remuneratória entre as regiões.

\section{Tabela 2 - Remuneração média por hora em valores reais dos professores públicos municipais agregada por estado - 2008-2016}

\begin{tabular}{|c|c|c|c|}
\hline Região & $\mathbf{2 0 0 8}$ & $\mathbf{2 0 1 6}$ & \% evolução \\
\hline Norte & $\mathrm{R} \$ 12,85$ & $\mathrm{R} \$ 17,49$ & 36,1 \\
\hline Nordeste & $\mathrm{R} \$ 10,67$ & $\mathrm{R} \$ 19,38$ & 81,7 \\
\hline Centro-Oeste & $\mathrm{R} \$ 13,89$ & $\mathrm{R} \$ 22,70$ & 63,5 \\
\hline Sudeste & $\mathrm{R} \$ 16,14$ & $\mathrm{R} \$ 20,39$ & 26,3 \\
\hline Sul & $\mathrm{R} \$ 16,10$ & $\mathrm{R} \$ 22,37$ & 38,9 \\
\hline
\end{tabular}

Fonte: Adaptado de Silva (2019).

Ao observar esse cenário por estado, é possível compreender o quanto os estados com complementação da União ampliaram suas remunerações médias. Dos 13 estados com maior ampliação real remuneratória, 7 tiveram recursos do Fundeb complementados pelo governo federal, com destaques para Ceará, Maranhão, Pernambuco e Bahia. Apenas Piauí e Pará ficaram de fora dos estados com municípios que apresentaram maior evolução. 


\section{Gráfico 2 - Diferença percentual em valores reais da média de remuneração docente dos professores públicos municipais no Brasil - 2008 - 2016}

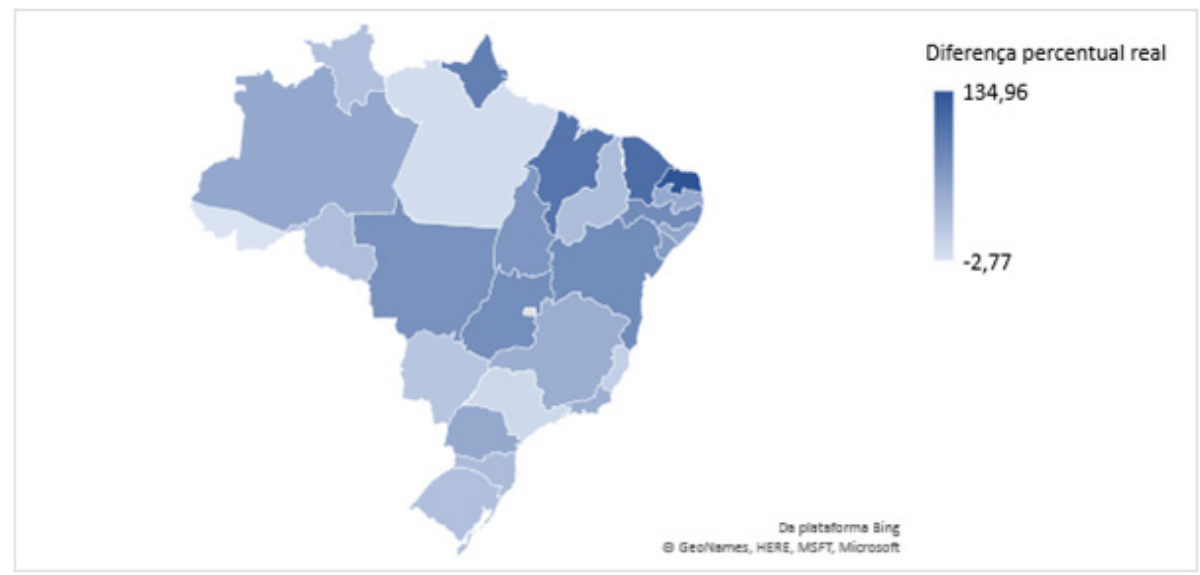

FONTE: Silva (2019). Elaborado pelo autor (2020).

Há que se considerar que, nessa disputa por parcelas do fundo público por parte do governo federal, houve ações por parte desse ente federado na busca por induzir os estados e municípios com redes/sistemas de ensino a adequarem a remuneração de seus profissionais do magistério a padrões mínimos.

Em que pese a Resolução n. 2/2009 do Conselho Nacional de Educação/Câmara da Educação Básica, que regulamentou a instituição de Planos de Carreira, Cargos e Remuneração, foi a lei n. 11.738/2008 que teve (e ainda tem) como objetivo a regulação do Piso Salarial Profissional Nacional PSPN, um vencimento inicial para a carreira dos profissionais do magistério no Brasil, para uma jornada máxima de 40 horas semanais, bem como a formação mínima, prevista inicialmente no art. 62 da LDB, de ensino médio na modalidade Normal, que também se destaca nesse contexto. Além da definição de quem são os profissionais do magistério público da educação básica, a referida lei também regula que, para a jornada de trabalho do profissional, a carga de trabalho em docência com os educandos deva ser no máximo $2 / 3$ de seu contrato de trabalho, estabelecendo que o restante seja destinado para atividades de planejamento e estudos, dentre outras.

Segundo Fernandes (2013), numa política como essa, regulada pela União e executada pelos entes federados, o objetivo finda-se na redução das desigualdades sociais provocadas pelas políticas econômicas, envoltas em um contexto de desigualdades regionais que caracterizam o Brasil, em que o governo federal regula de forma centralizada, age de forma suplementar em assistência 
técnica e financeira e deixa a cargo dos demais entes federados com redes/ sistemas de ensino os custos e o modelo de execução da política.

O índice de atualização anual do PSPN é baseado na variação do VAA do Fundeb para uma matrícula dos anos iniciais do ensino fundamental urbano nos dois últimos exercícios anteriores. Ou seja, o reajuste do piso salarial de 2015, por exemplo, é calculado pela variação percentual do valor anual por aluno entre 2013 e 2014, previsto para janeiro de cada ano subsequente.

Entre 2009 e 2018, o crescimento total do PSPN acompanhou a variação dos dois anos anteriores do VAA, com exceção à 2014, corrigido no ano posterior. Evidencia-se que, pela sua regulação, a evolução do PSPN está diretamente articulada com o Fundeb e a evolução do valor por aluno. Considerando que o Fundeb vincula no mínimo $60 \%$ de seus recursos ao pagamento da remuneração dos profissionais do magistério, o aumento do valor mínimo por aluno na redistribuição de recursos do fundo implica em maior potencial para os entes federados em alocarem recursos para a valorização da remuneração docente. Por estar ligado ao Fundeb, a política de reajuste do piso e do VAA estão diretamente ligadas. Nessa conexão, em que o Fundeb se coloca no centro da operação de possibilitar historicamente o endereço dos recursos em MDE para suas finalidades (FERNANDES, 2015), importa compreender que, apesar da política de fundos vincular um percentual mínimo de $60 \%$ para remuneração de profissionais da educação, ela não pode ser considerada como um teto, assim como o PSPN. A tabela seguinte auxilia nesse entendimento.

Tabela 3 - Evolução em valores nominais do PSPN e do Valor Anual Mínimo por Aluno no Fundeb para os anos iniciais do ensino fundamental - 2009 - 2018

\begin{tabular}{|c|c|c|c|c|}
\hline Ano & Piso & Reajuste aplicado & Valor por aluno & $\begin{array}{c}\text { Variação nos dois últimos anos do } \\
\text { valor por aluno }\end{array}$ \\
\hline 2009 & $\mathrm{R} \$ 950,00$ & - & $\mathrm{R} \$ 1.221,34$ & - \\
\hline 2010 & $\mathrm{R} \$ 1.024,67$ & $7,86 \%$ & $\mathrm{R} \$ 1.414,85$ & $8,92 \%$ \\
\hline 2011 & $\mathrm{R} \$ 1.187,14$ & $15,86 \%$ & $\mathrm{R} \$ 1.729,28$ & $15,84 \%$ \\
\hline 2012 & $\mathrm{R} \$ 1.451,00$ & $22,23 \%$ & $\mathrm{R} \$ 1.867,15$ & $22,22 \%$ \\
\hline 2013 & $\mathrm{R} \$ 1.567,00$ & $7,99 \%$ & $\mathrm{R} \$ 2.221,73$ & $7,97 \%$ \\
\hline 2014 & $\mathrm{R} \$ 1.697,39$ & $8,32 \%$ & $\mathrm{R} \$ 2.285,57$ & $18,99 \%$ \\
\hline 2015 & $\mathrm{R} \$ 1.917,18$ & $12,95 \%$ & $\mathrm{R} \$ 2.545,31$ & $2,87 \%$ \\
\hline 2016 & $\mathrm{R} \$ 2.135,64$ & $11,39 \%$ & $\mathrm{R} \$ 2.739,77$ & $11,36 \%$ \\
\hline 2017 & $\mathrm{R} \$ 2.298,83$ & $7,64 \%$ & $\mathrm{R} \$ 2.926,56$ & $7,64 \%$ \\
\hline 2018 & $\mathrm{R} \$ 2.455,35$ & $6,81 \%$ & $\mathrm{R} \$ 3.048,73$ & $6,82 \%$ \\
\hline- & Crescimento acumulado & $101,05 \%$ & - & $102,64 \%$ \\
\hline
\end{tabular}

Fonte: Adaptado de Siope (2019). 
Entretanto, o panorama da efetividade da lei apresentado pelo Ministério da Educação (2016) é alarmante. Em pesquisa realizada com os municípios brasileiros, $50,7 \%$ destes tem plano de carreira, somente $45,5 \%$ de gestões municipais cumprem a Lei do Piso e apenas $38,9 \%$ ofertam o mínimo de um terço da jornada de trabalho para atividades de planejamento e estudos fora de sala de aula. Com isso, concorda-se que o grande desafio para a valorização docente, carreira, remuneração e jornada de trabalho ainda permanece.

Políticas como o estabelecimento do PSPN causam estremecimentos locais e algumas resistências. Portanto, o desafio local, mediante uma política de indução do governo federal, é superar a contraposição regional quando a valorização da remuneração de professores não está na ordenação de prioridades do poder público.

Abicalil (2013) entende que o problema atual da educação básica e das possibilidades de ampliação da qualidade da educação via investimento federal perpassa pela pouca presença da União na educação básica. A questão da complementação do ente ao Fundeb, por exemplo, também perpassa por uma disputa, onde os estados com maior potencial de investimento pressionam a União para obter um recurso que é destinado para fundos estaduais de redistribuição com menores montantes arrecadados. É um certame político complexo, seja para a União e seu papel de ação de assistência supletiva e redistributiva, seja para os estados que garantem via recursos próprios um investimento mínimo, que pressionam a União por recursos complementares. O problema da pauta é o enfrentamento da desigualdade.

Ao mesmo tempo em que o fundo público, particularmente no âmbito da União, caminhou na tentativa de ampliar as condições remuneratórias dos municípios em regiões com menor potencial de investimento, efetivamente pela via do Fundeb, os encargos com o serviço da dívida pública assolam as finanças, particularmente do governo federal. No caso da dívida pública municipal, Silva (2019) explorou as informações da Secretaria do Tesouro Nacional e do Sistema de Informações Contábeis e Fiscais do Setor Público Brasileiro, tanto no cumprimento dos preceitos da lei de responsabilidade fiscal no que tange à dívida pública, como no percentual da execução orçamentária destinado aos encargos desta. O cenário é de que em torno de $90 \%$ dos 3.822 municípios analisados gastam menos de $3 \%$ do seu orçamento para este fim e devem menos de $50 \%$ de sua receita corrente líquida.

No caso do governo federal, apoia-se no estudo realizado anualmente pela Auditoria Cidadã da Dívida, que analisa as despesas da União, enfatizando os dispêndios com a dívida pública. Nesse cenário, é possível compreender o quanto as despesas do governo federal são impactadas pelos serviços de Juros 
e Amortização da Dívida Pública - JEAD. Na tabela abaixo, observa-se uma variação de 2011 a 2019 entre 38\% e 45\% do orçamento executado da União com tais serviços. Em termos de valores nominais, houve um crescimento constante até 2016, com uma variação negativa em 2017 e retomada de crescimento nos anos posteriores até 2019. Essa variação acompanha o total da execução orçamentária do ente federado.

\section{Tabela 4 - Orçamento executado do governo federal e discriminações percentuais de dispêndio para os serviços de juros e amortização da dívida pública comparados com percentual destinado à educação - 2011 - 2019}

\begin{tabular}{|c|c|c|c|c|}
\hline Ano & Percentual de Jead & Nominal (em bi R\$) & Percentual Educação & Executado da União \\
\hline 2011 & $45,05 \%$ & 708 & $2,99 \%$ & 1571 \\
\hline 2012 & $43,98 \%$ & 753 & $3,44 \%$ & 1712 \\
\hline 2013 & $40,30 \%$ & 718 & $3,70 \%$ & 1783 \\
\hline 2014 & $45,11 \%$ & 978 & $3,73 \%$ & 2168 \\
\hline 2015 & $42,43 \%$ & 962 & $3,91 \%$ & 2268 \\
\hline 2016 & $43,94 \%$ & 1130 & $3,70 \%$ & 2572 \\
\hline 2017 & $39,70 \%$ & 986 & $4,10 \%$ & 2483 \\
\hline 2018 & $40,66 \%$ & 1066 & $3,62 \%$ & 2621 \\
\hline 2019 & $38,27 \%$ & 1038 & $3,48 \%$ & 2711 \\
\hline
\end{tabular}

Fonte: Auditoria Cidadã da Dívida (2020). Dados elaborados pelo autor (2020).

Algo que também chama a atenção é o percentual investido em educação durante a série história. Observa-se, até 2016, um crescimento percentual, variando 0,2\% para baixo e retomando em 2017 0,4\%. Entretanto, há preocupação e uma tendência a partir de 2018, com quedas percentuais significativas na relação entre as despesas educacionais e o orçamento executado do governo federal.

Nesse contexto de disputa, certamente já se observa um efeito inicial das políticas de austeridade fiscal capitaneadas pelo novo projeto governamental, após a destituição da Presidente eleita democraticamente em meados de 2016, simbolizado pela Emenda Constitucional n. 95/2016, que estabeleceu um modelo de regime fiscal por 20 anos e que já trazia em outra análise a possibilidade de reflexos para as políticas educacionais no que tange à execução orçamentária (AMARAL, 2016).

Por ser uma política com amarras constitucionais, o Fundeb e a complementação da União para o fundo não parecem ser inicialmente afetados por esse novo modelo, seja no período de foco de análise da pesquisa (2008 - 
2016) ou até 2019, como é o caso da tabela acima, pois, nos anos de 2017, 2018 e 2019, manteve-se a complementação da União em percentual idêntico ao de 2016, $8,26 \%$ da receita estimada do referido fundo.

Todavia, alerta-se para a necessidade da aprovação de um Fundeb permanente, tendo em vista que essa política ocupa um lugar temporário na Constituição Federal, com prazo de término em 2020. Entende-se que é necessário que a complementação da União se torne mais efetiva e volumosa no que tange aos recursos complementados pelo governo federal. Entretanto, desde a discussão da Proposta de Emenda Constitucional em 2015, a mudança de perfil de gestão fiscal da União, em decorrência da destituição da Presidente já supracitada e a eleição do atual ocupante do Poder Executivo nacional, tornaram o debate em torno do Fundeb uma pauta secundária, mediante a pressão do mercado e dos ocupantes de ministérios em torno de reformas, sejam no campo trabalhista, previdenciário, tributário e/ou administrativo, algo preocupante para a manutenção de políticas de financiamento com cunho redistributivo e equitativo.

\section{CONSIDERAÇÕES FINAIS}

Uma concepção política de valorização do professor pode ser traduzida em um viés de luta, enfrentamentos e disputas históricas, em que o desdobramento da política educacional simboliza o estado atual desse embate (GROCHOSKA, 2015). Nessa perspectiva, compreender a política pública educacional de remuneração docente implica na importância dos marcos legais e a necessidade de alocação do fundo público para sua efetividade. Nesse viés, concorda-se com Camargo e Jacomini (2011, p. 159) que "há garantias jurídicas suficientes para que o professor tenha condições de trabalho, possibilidade de formação e remuneração mínima”.

Nesse viés, é possível afirmar que o período analisado (2008 - 2016) foi composto de uma série de avanços em torno da valorização da remuneração docente, com destaque para o estabelecimento de um PSPN e, especificamente na análise deste trabalho, a complementação financeira da União, que auxiliou na redução da desigualdade remuneratória média. $\mathrm{O}$ viés abordado neste trabalho enfatiza que, apesar da valorização real supracitada, há em curso uma disputa política pelo fundo público federal em que o dispêndio com os serviços de rolagem da dívida pública se apresenta como a maior despesa e, consequentemente, vultuosa alocação do fundo público para tal.

Portanto, são disputas políticas em que a financeirização da riqueza, via pagamentos de juros e amortização aos detentores de títulos da dívida pública e o aporte financeiro do governo federal na complementação da União para o Fundeb, 
visando a ampliação do direito à educação de qualidade e, consequentemente, melhoria da valorização dos professores pela ampliação de sua remuneração, parecem compor segmentos da dinâmica de disputa pelo fundo público, que, na ausência de uma política de fundos permanente com ampliação da participação da União no complemento do fundo, objeto de luta atual em vias de fim do Fundeb em 2020 como Emenda Constitucional no Ato das Disposições Constitucionais Transitórias, podem representar ameaças para o contexto de valorização docente apresentado.

\section{REFERENNCIAS}

ABICALIL, C. A. Sistema nacional de educação: os arranjos na cooperação, parceria e cobiça sobre o fundo público na educação básica. Educ. Soc., Campinas, v. 34, n. 124, p. 803-828, jul./set. 2013.

ARAUJO, R. L. S. Limites e possibilidades da redução das desigualdades territoriais por meio do financiamento da educação básica. 401 f. Tese (Doutorado em Educação) - Programa de Pós-Graduação em Educação, Faculdade de Educação, Universidade de São Paulo, São Paulo, 2013.

AMARAL, N. PEC 241/55: a "morte" do PNE (2014-2024) e o poder de diminuição dos recursos educacionais. Revista Brasileira de Política e Administração da Educação, Goiânia, v. 32, n. 3, p. 653 - 673, set./dez. 2016.

ANDERSON, P. Balanço do neoliberalismo. IN SADER, E; GENTILI, P. (orgs.). Pós-neoliberalismo: as políticas sociais e o Estado democrático. Rio de Janeiro: Paz e Terra, 1995.

AUDITORIA CIDADÃ DA DÍVIDA. Orçamento federal executado. Disponível em: <https://auditoriacidada.org.br/quem-somos/>. Acesso em: 07 mar. 2020.

BEHRING, E. R. BOSCHETTI, I. Política social: fundamentos e história. 9 ed. São Paulo: Cortez, 2011. 
BRASIL. Lei n. 11.738, de 16 de julho de 2008. Regulamenta a alínea "e" do inciso III do caput do art. 60 do Ato das Disposições Constitucionais Transitórias, para instituir o piso salarial profissional nacional para os profissionais do magistério público da educação básica. 2008. Diário Oficial [da] República Federativa do Brasil, Brasília, DF, 17 jul. 2008.

BRASIL. Lei $n^{\circ} 11.494$ de 20 de junho de 2007. Regulamenta o Fundo de Manutenção e Desenvolvimento da Educação Básica e de Valorização dos Profissionais da Educação - FUNDEB, de que trata o art. 60 do Ato das Disposições Constitucionais Transitórias; altera a Lei n. 10.195, de 14 de fevereiro de 2001; revoga dispositivos das Leis n. 9.424, de 24 de dezembro de 1996, 10.880, de 9 de junho de 2004, e 10.845, de 5 de março de 2004; e dá outras providências. 2007. Diário Oficial [da] República Federativa do Brasil, Brasília, DF, 21 jun. 2007.

BRASIL. Emenda Constitucional n. 53, de 19 de dezembro de 2006. Dá nova redação aos arts. $7^{\circ}, 23,30,206,208,211$ e 212 da Constituição Federal e ao art. 60 do Ato das Disposições Constitucionais Transitórias. 2006. Diário Oficial [da] República Federativa do Brasil, Brasília, DF, 19 dez. 2006.

BRASIL. Emenda Constitucional n. 14, de 12 de setembro de 1996. Modifica os arts. 34, 208, 211 e 212 da Constituição Federal e dá nova redação ao art. 60 do Ato das Disposições Constitucionais Transitórias. 1996. Diário Oficial [da] República Federativa do Brasil, Brasília, DF, 13 set. 1996.

BRASIL. Emenda Constitucional n. 95, de 15 de dezembro de 2016. Altera o Ato das Disposições Constitucionais Transitórias, para instituir o Novo Regime Fiscal, e dá outras providências. 2016. Diário Oficial [da] República Federativa do Brasil, Brasília, DF, 15 dez. 2016.

BRASIL. Relatório de cumprimento do piso salarial profissional nacional pelos entes federativos. Ministério da Educação. 2016. 
BRASIL. Conselho Nacional de Educação. Câmara da Educação Básica. Resolução n. 2 de 28 de maio de 2009. Fixa as Diretrizes Nacionais para os Planos de Carreira e Remuneração dos Profissionais do Magistério da Educação Básica Pública, em conformidade com o artigo $6^{\circ}$ da Lei $n^{\circ} 11.738$, de 16 de julho de 2008, e com base nos artigos 206 e 211 da Constituição Federal, nos artigos $8^{\circ}$, $\ 1^{\circ}$, e 67 da Lei $\mathrm{n}^{\circ}$ 9.394, de 20 de dezembro de 1996, e no artigo 40 da Lei no 11.494 , de 20 de junho de 2007. 2009. Diário Oficial [da] República Federativa do Brasil, Brasília, DF, 29 mai. 2009.

CAMARGO, R. B.; JACOMINI, M. A. Carreira e salário do pessoal docente da educação básica: algumas demarcações legais. Educação em foco, Belo Horizonte, ano 14, no 17 p. 129-167, jul. 2011.

FERNANDES, M. D. E. A valorização dos profissionais da educação básica no contexto das relações federativas brasileiras. Educação \& Sociedade, Campinas, v. 34, p. 1095-1111, 2013.

FERNANDES, M. D. E. Em tempo de valorização dos profissionais da educação. IN: Valorização dos profissionais da educação: formação, remuneração. Carreira e condições de trabalho. GOUVEIA, A. B. (org.). $1^{\text {a }}$ Ed. Editora Appris, Curitiba, 2015, p. 13 - 36.

GOUVEIA, A. B. SOUZA, A. R. de. A política de fundos em perspectiva histórica: mudanças de concepção da política na transição Fundef e Fundeb. IN: Em aberto: o Fundeb em perspectiva. PERES, A. J. S. VIDAL, E. M. (orgs). Brasília, v. 28, n. 93, p. 45-65, jan./jun. 2015.

GROCHOSKA, M. A. Políticas educacionais e a valorização do professor: carreira e qualidade de vida dos professores de educação básica do município de São José dos Pinhais/PR. 269 f. Tese (Doutorado em Educação) - Programa de Pós-Graduação em Educação, Setor de Educação, Universidade Federal do Paraná, Curitiba, 2015.

MASSON, G. Requisitos essenciais para a atratividade e a permanência na carreira docente. Educ. Soc., Campinas, v. 38, n. 140, p.849-864, jul./set. 2017.

OLIVEIRA, F. Surgimento do antivalor. IN: OLIVEIRA, F. (Org.). Os direitos do antivalor: a economia política da hegemonia imperfeita. Petrópolis: Vozes, 1998, p. 19 - 48. 
POCHMANN, M. Proteção social na periferia do capitalismo: considerações sobre o Brasil. São Paulo em Perspectiva, São Paulo, v. 18, n. 2, p. 3-16, 2004.

POULANTZAS, N. O Estado, o poder, o socialismo. Tradução de Rita Lima. $1^{a}$ Ed. São Paulo: Paz e Terra, 2015.

POGGI, G. A evolução do Estado Moderno: uma introdução sociológica. Rio de Janeiro: Zahar, 1981.

SALVADOR, E. Fundo público e seguridade social. São Paulo: Cortez, 2010a.

SALVADOR, E. Fundo público e políticas sociais na crise do capitalismo. Serv. Soc. Soc., São Paulo, n. 104, p. 605-631, out./dez. 2010 b.

SELZ, M. O raciocínio estatístico em sociologia. In: PAUGAM, Serge (Coord.). A pesquisa sociológica. Petrópolis, RJ: Vozes, 2015, p. 202-217.

SILVA, M. Q. da. Remuneração de professores públicos municipais no Brasil: execução orçamentária, partidos públicos e valorização docente (2008 - 2016). 247 f. Tese (Doutorado em Educação) - Programa de PósGraduação em Educação, Universidade Federal do Paraná, Curitiba, 2019.

SISTEMA DE INFORMAÇÕES SOBRE ORÇAMENTO PÚBLICO EM EDUCAÇÃO. Arquivos analíticos. Brasília: Ministério da Educação, 1968 2018. Disponível em:< http://www.fnde.gov.br/fnde-sistemas/sistema-siopeapresentacao/siope-apresentacao >. Acesso em: 03 mar. 2020.

SOUZA, A. R. A política educacional e seus objetos de estudo. Revista de Estudios Teóricos y Epistemológicos en Política Educativa, Ponta Grossa, v. 1, n. 1, 2016.

\section{Marcus Quintanilha da Silva}

Doutor em Educação pela Universidade Federal do Paraná. Professor do magistério superior na Faculdade São Braz. E-mail: marcusquintanlha@hotmail. com 